\title{
Patient-friendly pathology reports for patients with breast atypias
}

\author{
Sarah P. Rooney MD $^{1}$ (D) | Shirley Hoffman BA, MA ${ }^{1}$ | John C. Perrin BS $^{1}$ | \\ Kara J. Milliron MS, CGC $^{2}$ | Alexis V. Nees MD $^{3} \mid$ Julie M. Jorns MD $^{1}$
}

${ }^{1}$ Department of Pathology, Michigan Medicine, University of Michigan, Ann Arbor, MI, USA

${ }^{2}$ Department of Oncology, Michigan Medicine, University of Michigan, Ann Arbor, MI, USA

${ }^{3}$ Department of Radiology, Michigan Medicine, University of Michigan, Ann Arbor, MI, USA

Correspondence

Sarah P. Rooney, Department of Pathology, University of Michigan, Ann Arbor, Michigan, USA.

Email: rooneys@med.umich.edu

Breast atypias include atypical ductal hyperplasia (ADH), lobular neoplasia (LN), flat epithelial atypia (FEA), and apocrine atypia (AA). Diagnostic criteria for $\mathrm{ADH}$ and $\mathrm{LN}$ were established by Page et al, who noted a 4-5-fold increased risk of breast cancer with long-term followup. ${ }^{1}$ Similarly, Hartmann et al found $30 \%$ of patients with isolated $\mathrm{ADH}$ or LN developed breast cancer (invasive carcinoma or ductal carcinoma in situ [DCIS]) at 25-year follow-up. ${ }^{2}$ Breast cancer risk for isolated FEA and AA is less clear; however, these lesions have been noted to be associated with $\mathrm{ADH}$ and $\mathrm{LN}$. When diagnosed on core biopsy, $A D H$ is upgraded to cancer on excision in $20-30 \%$ of cases, whereas other atypias are upgraded $\leq 10 \%$ of the time. ${ }^{3}$ Although data are emerging that may allow some patients with breast atypias to be followed clinically, ${ }^{3}$ many institutions recommend excision, regardless of atypia type, when diagnosed on core biopsy.

Since breast atypias are risk markers of cancer, but not cancer themselves, patients may wait longer for next steps in care. This can lead to patient anxiety and feelings of neglect. We aimed to provide patients with comprehensible information about their breast atypia diagnoses in an attempt to ease anxiety.

Patients with first diagnoses of breast atypia on core biopsy (7/ 2015-1/2017) were mailed a copy of their pathology report along with a 1-page information sheet on their diagnosis. The contents of the information sheets were created by a multi-disciplinary team (SPR, SH, JCP, KJM, AVN, JMJ) and outlined basic diagnostic criteria, future risk of cancer, and likely next steps in care (Figure 1). A cover letter with contact information was also included in case the patient desired to speak with a breast pathologist (JMJ). Patients were given a survey at their first clinic visit to assess receipt of mailing, value of information, and patient comprehension. All patient materials complied with institutional standards for ease in reading, including fonts (Arial, Lucida), font size (12+ point), and formatting.
Forty patients had first diagnoses of atypia which included 21 (52.5\%) ADH, 8 (20\%) LN, 6 (15\%) FEA, 1 (2.5\%) AA, 2 (5\%) ADH and LN, 1 (2.5\%) LN and FEA, and 1 (2.5\%) ADH and FEA.

Mean time from diagnosis to first appointment was 29 days (range 6-121). Two (5\%) spoke with a pathologist via phone prior to first appointment. The majority (38/40; 95\%) received surveys at first appointment (one declined an appointment and one was seen 6 days after diagnosis, prior to clinic notification of need for survey).

About $47.4 \%(18 / 38)$ of patients returned surveys. Of the 17 who reported to have received the mailing, the majority $(16 / 17$; 88.9\%) reported that the information was helpful and understandable. Most (14/17; 77.8\%) reported that they "did not have breast cancer"; one patient did not answer this question and wrote "don't know" in the margin and 1 patient checked both "I have" and "I do not have" breast cancer boxes for this question. Of note, 1 patient reported that the mailing had been received but did not complete the remainder of the survey.

The majority (38/40; 95\%) of patients underwent subsequent excision with mean time from diagnosis to surgery of 66 days (range 21-140).

Pathology reports provide critical information which guides patient care. However, they can be detailed and complex, and therefore difficult to interpret. In recent years, much attention has been given to the use of standardized, synoptic pathology reporting to ensure that important diagnostic and staging elements are present and readily identifiable by treating clinicians. ${ }^{4,5}$ These efforts have been well-received by clinicians. ${ }^{6}$ Additional efforts have also been undertaken to help understand and improve clinician comprehension of pathology reports. ${ }^{7,8}$ However, many patients are become increasing active in their care, and also desire access to their pathology reports. 


\begin{tabular}{|c|c|c|c|}
\hline :MEALTH SYSTEM & $\begin{array}{l}\text { University of Michigan Health System } \\
\text { Department of Pathology } \\
\text { Anatomic Pathology } \\
1500 \text { East Medical Center Drive } \\
\text { Ann Arbor. M1 } 48109 \\
\text { (734) } 936-8798\end{array}$ & $\begin{array}{l}\text { Last Name: } \\
\text { First Name: } \\
\text { MRN: } \\
\text { Sex: Female } \\
\text { Physician: } \\
\text { Location: }\end{array}$ & \\
\hline \multicolumn{4}{|c|}{ SURGICAL PATHOLOGY REPORT } \\
\hline $\begin{array}{l}\text { Order Number: } \\
\text { Date Completed: }\end{array}$ & $\begin{array}{l}\text { SU-15-41004 } \\
\text { 7/8/2015 7:35 AM }\end{array}$ & $\begin{array}{l}\text { Date Received: } \\
\text { Date Collected: }\end{array}$ & $\begin{array}{l}\text { 7ח/2015 4:00 PM } \\
7 \pi / 2015 \text { 4:00 PM }\end{array}$ \\
\hline
\end{tabular}

Diagnosis:

A. Left breast, core biopsies: Focal atypical lobular hyperplasia (E-cadherin immunohistochemical stain confirmatory). Fibroadenomatous and fibrocystic change including cysts, columnar cell alteration and usual ductal hyperplasia, both with microcalcifications.

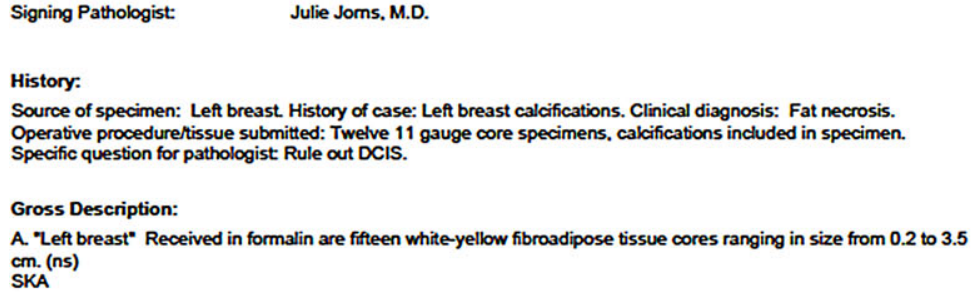

\section{Additional Information Regarding Your Diagnosis}

Your Primary Diagnosis is: Lobular neoplasia (atypical lobular hyperplasia (ALH)/ lobular carcinoma in-situ (LCIS).

\section{What is lobular neoplasia?}

Lobular neoplasia is NOT breast cancer. However, it is abnormal growth of cells within breast glands that does increase future risk of cancer. Lobular neoplasia is often referred to as ALH or LCIS. ALH and LCIS differ in amount of involvement of the glands, with ALH having lesser and LCIS having greater involvement. It is fairly common for patients to have some glands with ALH and others with LCIS.

\section{What is your risk?}

While most patients with lobular neoplasia will not get breast cancer, patients with estimated to be higher than for those without lobular neoplasia.

\section{What can you expect following your diagnosis of lobular neoplasia?}

Patients with the diagnosis of lobular neoplasia typically undergo excision (i.e. removal) of the tissue from the region of the biopsy to make sure that nothing worse is found. This is an uncommon event but may occur. Patients with lobular neoplasia may also choose to meet with other doctors and together may decide to pursue additional therapies aimed to reduce the future breast cancer risk.

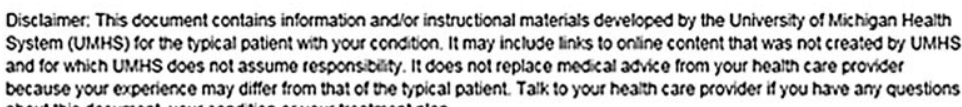

FIGURE 1 Example for pathology report and information sheet mailed to patient [Color figure can be viewed at wileyonlinelibrary.com]

Pathology reports, even in standardized and synoptic formats, are not "patient-friendly," or easily-comprehensible to the typical, nonmedical professional, patient. Thus, clinicians usually interpret diagnoses for patients. Many also seek published materials, often on patient education websites. However, these websites often have a broad range of information, much of which may not pertain to a specific diagnosis. Additionally, other online sites may not be credible and/or may contain misinformation.

We sought to create "patient-friendly" information sheets specific to breast atypias as patients with these diagnoses represent a vulnerable population that, because of delays in care (in our study 4 weeks on average from diagnosis to first appointment), may result 
in misinformed patients. In a worse-case scenario, a patient may believe that they have breast cancer, rather than a risk-associated lesion.

We had hoped to acquire more patients but found that, even at a large tertiary breast care center, many had either a prior or concurrent diagnosis of atypia or carcinoma and were excluded due to prior counseling/education. Thus, an obvious limitation of this study is the small size. However, in our small pilot study, all (16) survey responders reported that the information sheets were both understandable and helpful, supporting that they were beneficial. Also, 14 of 16 (87.5\%) responders noted that they did not have breast cancer, supporting patient comprehension.

Our findings support that "patient-friendly" supplemental information accompanying the pathology report is a beneficial addition that can help patients transition to next steps in care, especially when there are anticipated delays. All pathology reports may be able include "patient-friendly" information to assist with patient comprehension of their diagnosis. Notably, multi-disciplinary discussion will be vital in creating and updating such information to provide consistency in patient education and care.

\section{ORCID}

Sarah P. Rooney (iD http://orcid.org/0000-0002-8655-296X

\section{REFERENCES}

1. Page DL, Dupont WD, Rogers LW, Rados MS. Atypical hyperplastic lesions of the female breast: a long-term follow-up study. Cancer. 1985;55:2698-2708.

2. Hartmann LC, Degnim AC, Stanten RJ, Dupont WD, Ghosh K. Atypical hyperplasia of the breast - risk assessment and management options. N Engl J Med. 2015;372:78-89.

3. Calhoun BC, Collins BC. Recommendations for excision following core needle biopsy of the breast: a contemporary evaluation of the literature. Histopathol. 2016;68:138-151.

4. Leslie KO, Rosai J. Standardization of the surgical pathology report: formats, templates, and synoptic reports. Semin Diagn Pathol. 1994;11:253-257.

5. Markel SF, Hirsch SD. Synoptic surgical pathology reporting. Hum Pathol. 1991;22:807-810.

6. Lankshear S, Srigley J, McGowan T, Yurcan M, Sawka C. Standardized synoptic cancer pathology reports - so what and who cares? A population-based satisfaction survey of 970 pathologists, surgeons, and oncologists. Arch Pathol Lab Med. 2013;137:1599-1602.

7. Powsner SM, Costa J, Horner RJ. Clinicians are from Mars and pathologists are from Venus - Clinician interpretation of pathology reports. Arch Pathol Lab Med. 2000;124:1040-1046.

8. Valenstein PN. Formatting pathology reports - apply four design principles to improve communication and patient safety. Arch Pathol Lab Med. 2008;132:84-94. 